\title{
What do we know about maternal and perinatal mortality and morbidity audits in sub-Saharan Africa? A scoping literature review
}

\author{
Adelaide Lusambili, Joyline Jepkosgei, Jacinta Nzinga and Mike English
}

(Information about the authors can be found at the end of this article.)

Received 26 July 2018

Revised 21 September 2018 Accepted 19 November 2018

() Adelaide Lusambili,

Joyline Jepkosgei, Jacinta Nzinga and Mike English. Published by

Emerald Publishing Limited.

This article is published under the Creative Commons Attribution

(CC BY 4.0) licence. Anyone may reproduce, distribute, translate and create derivative works of this article (for both commercial and non-commercial purposes), subject to full attribution to the original publication and authors. The full terms of this licence may be seen at http://

creativecommons.org/licences/by/ 4.0/legalcode

The authors would like to thank Elizabeth Kyala and Metrine Saisi for their assistance in retrieving source materials for this review. The work of JN and JJ was supported by a Health Systems Research Initiative joint grant provided by the Department for International Development, UK (DFID), Economic and Social

Research Council (ESRC), Medical Research Council (MRC) and Wellcome Trust, Grant No. MR/M015386/1. ME and AL's work on this project were supported by a Wellcome Trust Senior Fellowship awarded to ME (No. 097170) with additional funds from a Wellcome Trust core grant awarded to the KEMRI-Wellcome Trust Research Programme (No. 092654).

\begin{abstract}
Purpose - The purpose of this paper is to provide a situational overview of the facility-based maternal and perinatal morbidity and mortality audits (MPMMAs) in SSA, their current efficacy at reducing mortality and morbidity rates related to childbirth.

Design/methodology/approach - This is a scoping literature review based on the synthesis of secondary literature.

Findings - Not all countries in SSA conduct MPMMAs. Countries where MPMMAs are conducted have not instituted standard practice, MPMMAs are not done on a national scale, and there is no clear best practice for MPMMAs. In addition, auditing process of pediatrics and maternal deaths is flawed by human and organizational barriers. Thus, the aggregated data collected from MPMMAs are not adequate enough to identify and correct systemic flaws in SSA childbirth-related health care.

Research limitations/implications - There are a few published literature on the topic in sub-Saharan Africa. Practical implications - This review exposes serious gaps in literature and practice. It provides a platform upon which practitioners and policy makers must begin to discuss ways of embedding mortality audits in SSA in their health systems as well as health strategies.

Social implications - The findings of this paper can inform policy in sub-Saharan Africa that could lead toward better outcomes in health and well-being.

Originality/value - The paper is original.
\end{abstract}

Keywords Mortality, Africa, Perinatal, Audits, Death reviews, Facility, Maternal, Sub-Saharan

Paper type Literature review

\section{Background}

A maternal mortality audit is a process that looks at the number and causes of deaths among women who die between conception and six weeks after delivery, while perinatal mortality audit looks at the stillbirths and early neonatal deaths (WHO, 2015, 2016; WB, 2011). The overall aim is to identify correctible deficiencies (such as omission in care, delayed or missed diagnosis, inappropriate missed drug administration and miscommunication) in order to improve the quality of safe motherhood, as well as to prevent future occurrences (WB, 2011; WHO, 2016; Owolabi et al., 2014). Morbidity audits look at the illness and problems which are not severe enough to cause death (Higginson et al., 2011; WHO, 2016).

In HICs, hospitals and other health care facilities have long conducted morbidity and mortality audits to identify deficiencies in health care provision and ways to improve patient outcomes (Kurinczuk et al., 2014; Luz et al., 2014). Routine facility morbidity and mortality audits have been linked to improved quality of care and better health outcomes (WHO, 2004, 2016). Reviews of maternity-related deaths, which began in the 1950s (Short, 1961), have proved especially 
effective at identifying potential contributing factors and reducing childbirth-associated mortality (Merali et al., 2014; Pattinson et al., 2009).

World Health Organization (WHO) (2001) published the first guidelines for conducting maternal death reviews (MDRs) in 1996 (revised in 2001). In 2004, WHOs "Beyond the numbers: reviewing maternal deaths and complications to make pregnancy safer" analyzed MDR data from audits and offered comprehensive suggestions on how to prevent deaths. In 2012, WHO and partners introduced maternal death surveillance and response (MDSR), which outlined a new, evidence-based approach to maternity-related health care that providers could use to improve their own practices (WHO, 2013). More recently, there has been an emphasis to explore causes of stillbirth and neonatal death, in order to identify avoidable contributing factors, as part of existing MDRs.

Not all countries in SSA have facilities for conducting death reviews. Countries that conduct death reviews have now modified the standard MDSR to include perinatal audits, or maternal and perinatal death surveillance and response (MPDSR). For example, Sierra Leone launched the National Maternal Death Surveillance and Response Technical Guidelines in 2015. The new guidelines moved beyond MDRs, to surveillance and response, taking actions to prevent future deaths. Burkina Faso Ministry of Health introduced the National MDSR system and guidelines to respond to the country's high maternal mortality rate in 2012, improving data collection and surveillance by incorporating use of mobile phones and routine reporting forms. By 2010, Kenya, South Africa (SA), Malawi, Botswana, Ghana, Tanzania, Uganda and Nigeria had instituted procedures for auditing maternal and neonatal mortality, based on WHO recommendations, on how health care facilities should conduct MPDSRs.

Overall, as literature attests, some SSA countries are conducting MPMM audits yet it is not clear whether the data collected are linked to improved quality of maternal and neonatal health considering the sobering numbers of deaths in facilities. Furthermore, very little is known about the processes and efficacy of the MMA data that are being collected. The aim of this review is to improve our understanding on this topic by providing a situational overview of the facility-based maternal and perinatal morbidity and mortality audits (MPMMAs) in SSA, their current efficacy at reducing mortality and morbidity rates related to childbirth.

\section{Methods}

\section{Step 1}

Inclusion criteria. The search was limited to SSA. Sub-Saharan Africa in this paper denotes countries geographically located south of the Sahara. SSA was chosen because it has the highest maternal and neonatal deaths worldwide. The research team (consisting of social scientists and a clinical epidemiologist) defined the search parameter. Both qualitative and quantitative studies in academic journals including MPMMAs published between 2008 and 2017; empirical papers containing sections on audit methods and processes; papers containing reflection on audits, quality of health and patient safety and articles written in English - both primary and secondary research works were included.

Exclusion criteria. Papers that did not meet the inclusion criteria above; book monographs; papers not in English language were excluded.

\section{Step 2}

Studies were selected by searching PubMed and HINARI databases for "maternal" or "perinatal" and "morbidity" or "mortality," "low-middle-income countries" (LMICS)" or "developing countries."

\section{Step 3}

The search yielded 1,678 papers. Authors screened the papers for duplicates and omitted 1,533 papers. Additional screening was conducted by two authors ( $\mathrm{AL}$ and $\mathrm{JJ}$ ) to look at the relevance of the remaining papers - as to whether they met the inclusion criteria. The authors omitted 
125 papers leaving 25 eligible papers. Non-peer-reviewed literature included reports, guidelines and policies obtained (largely through author contacts) from international health organizations and government ministries of health.

\section{Step 4}

All studies retrieved were read by the research team to understand the scale of audits in LMIC. Each team member read the materials and entered into a summary table (Tables Al and All). Aspects of the information collected included: how mortality audit data were being conducted in SSA. In particular, the methods and processes that were in place; what challenges exist; the effectiveness of the data; what standards and tools were in place; and what research gaps exist.

The resulting analysis reflects frequent collective discussions on how to evaluate and interpret the data collected (Figure 1).

\section{Findings}

As detailed below, findings exhibit that MPMMAs are not a standard operating procedures across SSA. The varied approaches that SSA countries have used over time in collecting MPMMA data make it difficult to evaluate the data collected; and systematic and human factors undermine the effectiveness of MPMMAs.

\section{Variability undermines the usefulness of MPMMA data}

This review shows many different auditing approaches SSA countries have used over time and in different settings, so it is difficult to evaluate and interpret the MPMMA data collected. Some MPMMAs, for instance, "near miss" cases, where potentially life-threatening incidents did not result in death, and some did.

\section{Figure 1 PRISMA chart of the selection of papers in review}

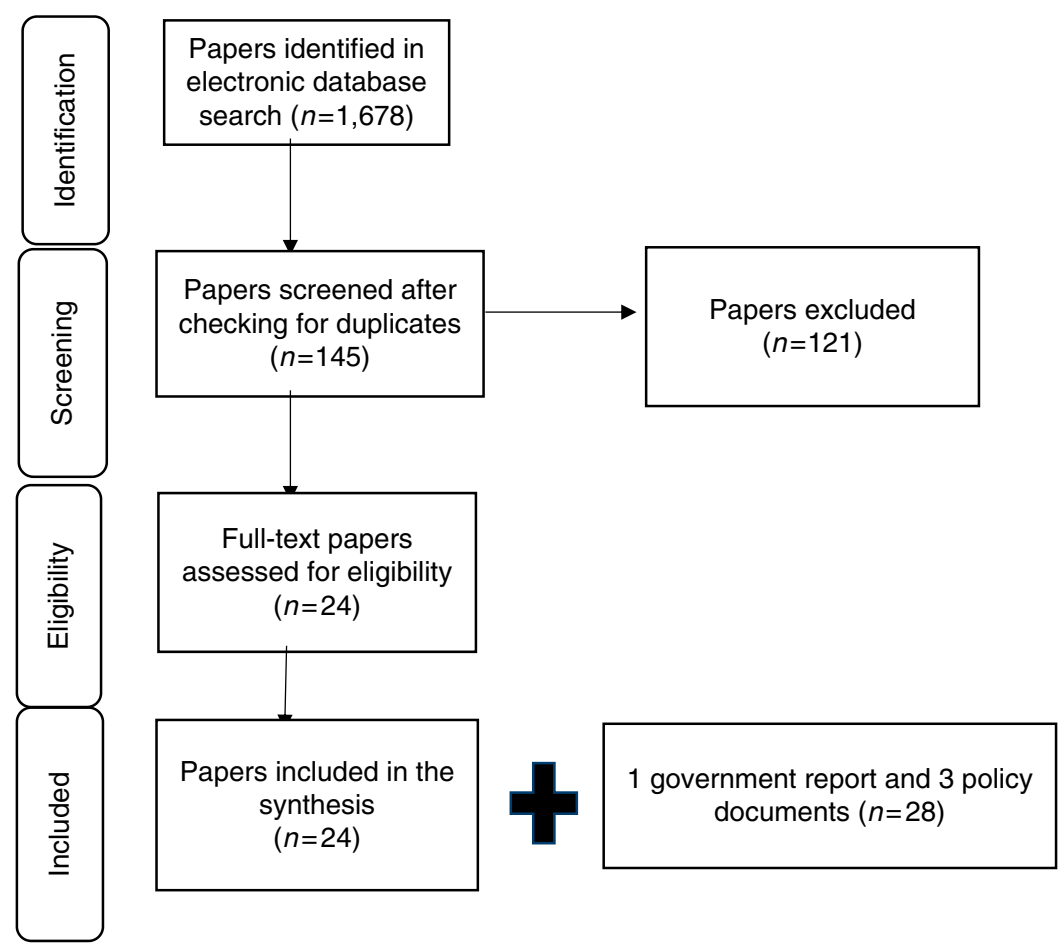


Other variable approaches included clinical audits - MDRs only, vs maternal and perinatal death reviews (MPDR) - and more in-depth confidential inquiries into maternal deaths (Agaro et al., 2016; Combs Thorsen et al., 2014, Madzimbamuto et al., 2014). By 2010, many SSA countries - SA, Botswana, Malawi and Ghana - had all introduced nationally supported procedures for systematically auditing maternal and neonatal mortality and morbidity. To date, numerous SSA African countries (Chad, Zimbabwe, Mozambique, Congo and Somalia) have either made minimal progress or yet to initiate a national MPMMA process. Several other countries (Tanzania, Uganda, Malawi, Nigeria, Kenya, Burkina Faso and SA) are conducting facility-based death reviews and using MDSRs/MPDSR (Agaro et al., 2016; Combs Thorsen et al., 2014; Kongnyuy and Van Den Broek, 2008; Rhoda et al., 2014; Richard et al., 2009).

This review revealed the degree to which MPMMAs are not yet standard operating procedure, promulgated by national governments in Sub-Saharan Africa. Where African MPMMAs do take place, they are initiated by individual health care facilities, often at great distances from one another (Musafili et al., 2017; Hofman and Mohammed, 2014). Rather than being conducted frequently according to a prescribed procedure, as in developed countries, African MPMMAs are generally undertaken in an ad hoc manner, occur in facilities that are widely dispersed geographically and include little or no outside supervision (Agaro et al., 2016; Van Hamersveld et al., 2012; Hofman and Mohammed, 2014). These features go far to explain the variability in methodologies used, which undermines the usefulness of the data. The literature suggests that to standardize MPMMAs, they need undertaken as part of a coordinated national effort (WB, 2011; WHO, 2016).

\section{Systemic and human factors undermining MPMMAs outcomes in SSA}

While MPMMAs have improved patient outcomes in HICs, in SSA, their implementation and success has been slow. This lack of progress in instituting standard mortality reviews has in part contributed to SSA's failure to achieve WHO's Millennium Development Goals (4 and 5) and Social Development Goal (3) to improve maternal health. Maternal and perinatal mortality rates remain significantly higher than in other countries; conditions in care facilities are frequently unsafe, medical errors are rife (WHO, 2013; Kinney et al., 2010) and the vast majority of SSA countries register childbirth-related deaths as having "no attributable cause" (WHO, 2010).

A 2010 WHO report on Malawi's effort, however, revealed that even where nationally supported, partly supervised and conducted according to standard MMNA protocols, the usefulness of these MPMMAs was undermined by a variety of issues, both cultural and systemic. The WHO report specifically cited: insufficient procedural knowledge, meager record keeping skills, insufficient data management skills and fear of being blamed for poor outcomes (see also Vink et al., 2013; Kongnyuy and Van Den Broek, 2008).

Farther, lessons learned from this review indicate that, where audits are conducted, MPMMAs meeting is not regular (Van Hamersveld et al., 2012; Agaro et al., 2016; Angelo et al., 2010; Vink et al., 2013). Yet, frequent mortality meetings are an effective way of learning how to prevent maternal and perinatal deaths as well, providing opportunities for acknowledging good care/practice and management. Similar findings were also reported in a study conducted in Burkina Faso (Richard et al., 2009), Uganda (Agaro et al., 2016), Nigeria (Hofman and Mohammed, 2014) and Malawi (Vink et al., 2013; Bakker et al., 2011). Research conducted in Malawi, Nigeria, Tanzania, Botswana and Uganda revealed a lack of knowledge and understanding about the importance of audits among hospital staff (Armstrong et al., 2014; Kongnyuy and Van Den Broek, 2008; Musafili et al., 2017; Van Hamersveld et al., 2012). Van et al. and Armstrong et al. found a lack of commitment among staff to conduct audits in Tanzania. In part, these barriers may be amplified by limited organizational support as the key health decision makers did not attend audit meetings. Supervision of mortality reviews is also inadequate (oversight from Ministry of Health) (Hofman and Mohammed, 2014; Agaro et al., 2016; Madzimbamuto et al., 2014; Vink et al., 2013).

This review also found that data reporting during the audit meeting were poor and incomplete (standards are not clearly set) with clinical records lacking in some audits - no discussion about the primary cause of death, final cause of death, avoidable factors, morbidity, missed opportunities and action plan. 
Since 2011, the Government of Kenya changed MDSR to include MPDSR (WHO, 2011), thus making it mandatory for hospitals to report maternal deaths (WHO, 2011). Although reporting childbirth-related deaths is done routinely, evidence shows that, the majority of the hospital facilities where standard forms are provided, health care staff fail to fill them out accurately and completely; no effort is made to analyze the information collected to find out how to improve conditions, practices and outcomes; and audits are not followed by changes designed to improve health outcomes $(\mathrm{KMOH}, 2014 \mathrm{a}, \mathrm{b})$.

Tanzania instituted MPDR in 2006. In 2010, however, Angelo et al. found that although maternal and perinatal mortality audits in Tanzania were a standard health care policy, the audits were limited in scope, and when carried out, were not standardized. The few hospitals that conducted MPDR audits did so only irregularly, kept no records of meetings, discussions, decisions or remedial actions taken. In addition, audit committees did not include key hospital decision makers, and health care workers were not made aware of audits having taken place.

Four years later, a study by Armstrong et al. found that little had changed. The MPDR system was still of insufficient quality to serve as the basis for identifying problems associated with maternal and perinatal deaths (Armstrong et al., 2014). Care facilities were given no guidelines on how to report facility-based maternal and perinatal deaths. The study also established that even where MPDR were conducted, those conducting reviews at the hospital were unable to identify challenges and solutions. In most cases, no remedial actions were taken. Where responses did take place, they were insufficient to remedy existing deficiencies that may have contributed to higher mortality rates.

Compared with other countries in SSA, SA seems to be the only country that has made progress toward this course. Created to help health care facilities conduct standardized mortality audits, SA's perinatal problem identification program (PPIP) is credited with reducing the rate of avoidable perinatal deaths and substantially improving the quality of health care (Rhoda et al., 2014). A PPIP's mortality review uses a participatory team approach, with nurses and doctors working together to analyze causes of death. Mortality meetings are frequent - every death is reviewed and summarized within 24h (Patrick and Stephen, 2008). All review team participants are asked to submit recommendations, and PPIP data are used to identify and rectify loopholes in the health care system that may lead to future deaths (Belizan et al., 2011; Rhoda et al., 2014; Patrick and Stephen, 2008). The PPIP process entails: data collection, "the preparatory meeting," mortality review meeting, epidemiological and content analysis and recommendations.

The plethora of research from SSA points to health care staffs' fear of being blamed for poor outcomes as a contributing factor to poor reporting (Kongnyuy and Van Den Broek, 2008; Combs Thorsen et al., 2014). Similarly, poor recording may be due to both insufficient resources to implement changes (Bakker et al., 2011; Kongnyuy and Van Den Broek, 2008) and insufficient value placed on teamwork (Van Hamersveld et al., 2012; Hofman and Mohammed, 2014; Lewis, 2014). These findings point toward the urgent need to train MPDR audit committees in SSAs and the need to institute incentives to motivate relevant health care staff to see the value of attending audit meetings.

\section{Discussions}

Based on WHO's guidelines for maternal and perinatal mortality audits, a successful death audit must: select a committee of diverse professionals (clinicians, hospital administrators and hospital representatives) and have a clearly defined leadership - including the chair, case/data presenter and a secretary; ensure that standards of good practice are available; certify that all deaths that occurred in the facility during a defined period of time are available; document the circumstances that led to each death; develop a clinical death summary file; and organize the MDR session in advance by arranging meeting venue, informing participants and providing a schedule of the review (WHO, 2004, 2005, 2006; see also De Brouwere et al., 2013). Farther, during the death review audit meetings, the chair must encourage a non-discriminatory environment to encourage honest discussions. Results from the previous audit meetings must be re-evaluated, clinical summary of each case presented and a systematic case analysis conducted to allow an understanding to the chain of events that led to the death. Death audits meetings must conclude with recommendation and an action plan.

\begin{tabular}{l|l|l} 
PAGE 196 & INTERNATIONAL JOURNAL OF HUMAN RIGHTS IN HEALTHCARE & VOL. 12 NO. 32019
\end{tabular} 
The current literature review shows limitations in the way, audits are being conducted in SSA. Recommended guidelines are not followed, which raises questions as to whether facilities that conduct audits have knowledge about these tools. This review also highlights potential areas of exploration that can be considered in strengthening audits as a quality improvement tool. Although MPMMAs in SSA are taking place at the facility levels, findings showed that procedures used have not been standardized. Reporting is also spotty, leaving scant data about the process and its results, either locally or nationally. The findings also underscore the lack of aggregation of facility level data with the community data. In SSA, most of the births take place in the communities. There is therefore an unclear description or reporting of events that took place at the community level which might indirectly or directly have contributed to maternal or new-born deaths. While there are studies on community level verbal autopsies, these are not integrated with the data from facilities as well. This highlights a gap that needs to be addressed, to ensure death causing factors attributed to dynamics at the community and facility levels are addressed. These findings are consistent with findings from other LMICs outside SSA, for example, Bangladesh, Solomon Islands (Sandakabatu et al., 2018); Brazil (Luz et al., 2014) and India (Paily et al., 2014).

Literature on MPMMs has put emphasis on how human and organizational factors have been a barrier to successful implementation of death reviews. While these factors are central, it is important to highlight that the ability of audit teams to review cases, draw lessons and inform service delivery frequently depends on team members' ability to share adverse information, disclose errors, and seek help and feedback from other team members and the administration, without fear of punitive measures (Lewis, 2014). Morbidity and mortality review can also be affected by the larger organizational and institutional context, and can be influenced by availability of resources and leadership support. Given the abundance of evidence that medical errors are largely attributable to systems rather than individuals; moreover, improving quality of care requires a more rigorous definition of the systems and methodology required to assess many different factors that may contribute to birth-related deaths (Lewis, 2014; Hofman and Mohammed, 2014; WHO, 2013).

The lack of understanding, inadequate supervision and a lack of skills among hospital teams as highlighted in the literature calls for the need for a cultural shift on how audits should be conducted. Literature suggests that, apart from SA where PPIP is used, audits are still fragmented and do not exist in many countries. Where audits have been successful like the developed countries, evidence shows that they are carried out by multi-disciplinary audit teams whose members meet regularly to review cases, identify challenges and solutions (Rhoda et al., 2014; Patrick and Stephen, 2008). This success, in part, has been due to effective guidelines and standardized frameworks in which multi-professional teams use during audits, which is lacking in many countries of SSA.

Current literature identifies gaps with regard to how MPMMAs are conducted in SSA countries. Rather than focusing on structural factors, there is need for research to explore issues around the audit processes as well as the context in which audits are conducted. For example, institutional and inter-professional contexts are useful in supporting health care professionals. Institutional support provides a favorable enabling environment for collaborative teamwork, ensures resources such as adequate staffing are available and supports best practice initiatives. Reduction of medical errors and improving quality of care require more system approach to address the multiple factors underlying medical errors that are beyond individuals (Collins et al., 2009; Walton, 2004). A systems approach is important in part because it promotes a blame-free environment, in which hospital staff at all levels, and patients, are all stakeholders. A systems approach will also provide the organizational structure health professionals need to collect, review and report data on adverse events, errors and near misses to improve hospital.

Recognizing the need to support countries in maternal health care, however, literature highlights the need for clear implementation guidelines for execution of mortality reviews and an enabling environment with support from governments (Abebe et al., 2017; Higginson et al., 2011; Lewis, 2014). WHO recommends the need for legal and ethical frameworks in setting up and conducting death reviews (WHO, 2016). The absence or existence of legal protection influences the ability of audit team members to willingfully take part in audits. The need for a legal framework 
to ensure that deaths are reported and discussed while ensuring accountability and confidentiality of individuals involved and the information gathered is therefore important (see also Hodorogea and Friptu, 2014; Paily et al., 2014).

\section{Conclusions}

There is need to strengthen the quality of facility level reviews in hospitals where they are being conducted, as well as encourage and provide frameworks that can guide those hospitals that are not undertaking this process to do so. Even where data are being collected like for the case of Tanzania (Armstrong et al., 2014), there is need to identify challenges and solutions to increase accountability of professionals and to improve quality of care. We conclude that while the implementation of mortality audits in SSA is slowly progressing, however, there is need to consider the more intangible human aspects that may directly or indirectly influence the success of implementation of such interventions. More research is needed on the social cultural context in which MPMMSs are conducted including processes and procedures, ways community mortality data can be aggregated with the facility data as a way for strengthening health systems and strengthening audit guidelines, frameworks and policies in SSA to improve audits.

\section{Limitations}

This is a scoping paper. There are a few published studies on this topic in sub-Saharan Africa.

\section{References}

Abebe, B., Busza, J., Hadush, A., Usmael, A., Zeleke, A.B., Sita, S., Hailu, S. and Graham, W.J. (2017), "We identify, discuss, act and promise to prevent similar deaths': a qualitative study of Ethiopia's maternal death surveillance and response system", BMJ Glob Health, Vol. 2 No. 2, p. e000199, doi: 10.1136/ bmjgh-2016-000199.

Agaro, C., Beyeza-Kashesya, J., Waiswa, P., Sekandi, J.N., Tusiime, S., Anguzu, R. and Kiracho, E. (2016), "The conduct of maternal and perinatal death reviews in Oyam District, Uganda: a descriptive cross-sectional study", BMC Womens Health, Vol. 16 No. 38, pp. 38-51.

Alexandre, D., Caroline, T. and Pierre, F. (2009), "Improving obstetric care in low-resource settings: implementation of facility-based maternal death reviews in five pilot hospitals in Senegal", Human Resource for Health, Vol. 7 No. 61, doi: 10.1186/1478-4491-7-61.

Allanson, R.E. and Pattinson, R.C. (2015), "Quality-of-care audits and perinatal mortality in South Africa", Bull World Health Organ, Vol. 93 No. 6, pp. 424-8, doi: 10.2471/BLT.14.144683.

Angelo, S.N., Urassa, D.P., Pembe, A.B., Kisanga, F. and Van Roosmalen, J. (2010), "Factors for change in maternal and perinatal audit systems in Dar es Salaam hospitals, Tanzania", BMC Pregnancy and Childbirth, Vol. 10, pp. 29-37.

Armstrong, C.E., Lange, I., Magoma, M., Ferla, C., Filippi, V. and Ronsmans, C. (2014), "Strengths and weaknesses in the implementation of maternal and perinatal deathreviews in Tanzania: perceptions, processes and practice", Tropical Medicine \& International Health, Vol. 19 No. 9, pp. 1087-95, available at: https://doi.org/10.1111/tmi.12353

Bakker, W., Van Den Akker, T., Mwagomba, B., Khukulu, R., Van Elteren, M. and Van Roosmalen, J. (2011), "Health workers' perceptions of obstetric critical incident audit in Thyolo District, Malawi", Tropical Medicine \& International Health, Vol. 16 No. 10, pp. 1243-50.

Belizan, M., Bergh, A.-M., Cilliers, C., Pattinson, R.C. and Voce, A. (2011), "Stages of change: a qualitative study on the implementation of a perinatal audit programme in South Africa”, BMC Health Services Research, Vol. 11 No. 1, p. 243, doi: 10.1186/1472-6963-11-243.

Collins, M.E., Block, S.D., Arnold, R.M. and Christakis, N.A. (2009), "On the prospects for a blame-free medical culture", Social Science \& Medicine, Vol. 69 No. 9, pp. 1287-90, doi: 10.1016/j.socscimed.2009.08.033.

Combs Thorsen, V., Sundby, J., Meguid, T. and Malata, A. (2014), "Easier said than done!: methodological challenges with conducting maternal death review research in Malawi", BMC Medical Research Methodology, No. 14, p. 29, doi: 10.1186/1471-2288-14-29. 
De Brouwere, V., Zinnen, V. and Delvaux, T. (2013), How to Conduct Maternal Death Reviews (MDR): Guidelines and Tools for Health Professionals, International Federation of Gynecologists and Obstetricians, London.

Higginson, J., Walters, R. and Fulop, N. (2011), "Mortality and morbidity meetings: an untapped resource for improving the governance of patient safety?", BMJ Quality and Safety, Vol. 21 No. 7, pp. 576-85.

Hodorogea, S. and Friptu, V. (2014), "The Moldovan experience of maternal death reviews", BJOG: An International Journal of Obstetrics and Gynaecology, Vol. 121 No. 4, pp. 81-5.

Hofman, J.J. and Mohammed, H. (2014), "Experiences with facility-based maternal death reviews in northern Nigeria", International Journal of Gynecology \& Obstetrics, Vol. 126 No. 2, pp. 111-4.

Kerber, K.J., Mathai, M., Lewis, G., Flenady, V., Erwich, J.J., Segun, T., Aliganyira, P., Abdelmegeid, A., Allanson, E., Roos, N., Rhoda, N., Lawn, J.E. and Pattinson, R. (2015), "Counting every stillbirth and neonatal death through mortality audit to improve quality of care for every pregnant woman and her baby", BMC Pregnancy and Childbirth, Vol. 15 No. S2, doi: 10.1186/1471-2393-15-S2-S9.

Kinney, M.V., Kerber, K.J., Black, R.E., Cohen, B., Nkrumah, F., Coovadia, H., Nampala, P.M., Lawn, J.E., Axelson. H., Bergh, A.M., Chopra, M., Diab, R., Friberg, I., Odubanjo, O., Walker, N. and Weissman, E. (2010), "Science in action: saving the lives of Africa's mothers, newborns, and children working group", Ke PLoS Medicine, Vol. 7 No. 6, p. e1000294, doi: 10.1371/journal.pmed.1000294.

KMOH (2014a), Kenya's Firstconfidential Enquiry into Maternal Deaths 2014, Reproductive and Maternal Health Services Unit, Nairobi.

$\mathrm{KMOH}$ (2014b), "A review of the implementation of maternal and perinatal deaths surveillance and response (MPDSR) at facility and community level in selected Counties in Kenya", Kenya Ministry of Health, Nairobi, available at: www.ncbi.nlm.nih.gov/pmc/articles/pmc5620333/ (accessed September 20, 2018).

Kongnyuy, E.J. and Van Den Droek, N. (2008), "The difficulties of conducting maternal death reviews in Malawi”, BMC Pregnancy Childbirth, Vol. 21 No. 4, pp. 149-55, doi: 10.1016/j.wombi.2008.08.002.

Kurinczuk, J.J., Draper, E.S., Field, D.J., Bevan, C., Brocklehurst, P., Gray, R., Kenyon, S., Manktelow, B.N., Neilson, J.P., Redshaw, M., Scott, J., Shakespeare, J., Smith, I. K. and Knight, M. (2014), "Experiences with maternal and perinatal death reviews in the UK - the MBRRACE-UK programme", BJOG: An International Journal of Obstetrics and Gynaecology, Vol. 121 No. S4, pp. 41-6.

Lewis, G. (2014), "The cultural environment behind successful maternal death and morbidity reviews", BJOG: An International Journal of Obstetrics and Gynaecology, Vol. 121 No. 4, pp. 24-31.

Luz, A.G., Osis, M.J., Ribeiro, M., Cecatti, J.G. and Amaral, E. (2014), "Perspectives of professionals participating in the Brazilian network for the surveillance of severe maternal morbidity regarding the implementation of routine surveillance: a qualitative study", Reproductive Health, Vol. 11 No. 1, p. 29, doi: 10.1186/1742-4755-11-29.

Madzimbamuto, F.D., Ray, S.C., Mogobe, K.D., Ramogola-Masire, D., Phillips, R., Haverkamp, M., Mokotedi, M. and Motana, M. (2014), "A root-cause analysis of maternal deaths in Botswana: towards developing a culture of patient safety and quality improvement", BMC Pregnancy Childbirth, Vol. 14 No. 231.

Merali, H.S., Lipsitz, S., Hevelone, N., Gawande, A.A., Lashoher, A., Agrawal, P. and Spector, J. (2014), "Audit-identified avoidable factors in maternal and perinatal deaths in low resource settings: a systematic review”, BMC Pregnancy Childbirth, Vol. 14 No. 280.

Musafili, A., Persson, L.Å., Baribwira, C., Påfs, J., Mulindwa, P.A. and Essén, B. (2017), "Case review of perinatal deaths at hospitals in Kigali, Rwanda: perinatal audit with application of a three-delays analysis", BMC Pregnancy Childbirth, Vol. 17 No. 1, p. 85, doi: 10.1186/s12884-017-1269-9.

Nakibuuka, V.K., Okong, P., Waiswa, P. and Byaruhanga, R.N. (2012), "Perinatal death audits in a peri-urban hospital in Kampala, Uganda”, African Health Sciences, Vol. 12 No. 4, pp. 435-42.

Owolabi, H., Ameh, C.A., Bar-Zeev, S., Adaji, S., Kachale, F. and van den Broek, N. (2014), "Establishing cause of maternal death in Malawi via facility-based review and application of the ICD-MM classification", Royal College of Obstetricians and Gynaecologists, Vol. 4, pp. 95-101.

Paily, V.P., Ambujam, K., Rajasekharan Nair, V. and Thomas, B. (2014), "Confidential review of maternal deaths in Kerala: a country case study", BJOG: An International Journal of Obstetrics and Gynaecology, Vol. 121 No. 4, pp. 61-6.

Patrick, M.E. and Stephen, C.R. (2008), "Child PIP: making mortality meaningful by using a structured mortality review process to improve the quality of care that children receive in the South African Health System", South African Journal of Child Health, No. 2, pp. 38-42. 
Pattinson, R., Kerber, K., Waiswa, P., Day, L.T., Mussell, F., Asiruddin, S.K., Blencowe, H. and Llawn, J.E. (2009), "Perinatal mortality audit: counting, accountability, and overcoming challenges in scaling up in low- and middle-income countries", International Journal of Gynecology \& Obstetrics, Vol. 107 No. 1, pp. 113-21.

Rhoda, N.R., Greenfield, D., Muller, M., Prinsloo, R., Pattinson, R.C., Kauchali, S. and Kerber, K. (2014), "Experiences with perinatal death reviews in South Africa-the perinatal problem identification programme: scaling up from programme to province to Country", BJOG: An International Journal of Obstetrics and Gynaecology, Vol. 121 No. 4, pp. 160-6.

Richard, F., Ouedraogo, C., Zongo, V., Ouattara, F., Zongo, S., Gruenais, M.E. and De Brouwere, V. (2009), "The difficulty of questioning clinical practice: experience of facility-based case reviews in Ouagadougou, Burkina Faso", BJOG: An International Journal of Obstetrics and Gynaecology, Vol. 116 No. 1, pp. 38-44.

Sandakabatu, M., Nasi, T., Titiulu, C. et al. (2018), "Evaluating the process and outcomes of child death review in the Solomon Islands", Archives of Disease in Childhood, Vol. 103, pp. 685-90.

Short, C.W.R. (1961), "Causes of maternal death among Africans in Kampala, Uganda", BJOG: An International Journal of Obstetrics \& Gynaecology, Vol. 68 No. 1, pp. 44-51.

Smith, H., Ameh, C., Roos, N., Mathai, M. and van den Broek, N. (2017), "Implementing maternal death surveillance and response: a review of lessons from country case studies", BMC Pregnancy and Childbirth, Vol. 17, pp. 233-42.

Van Hamersveld, K.T., den Bakker, E., Nyamtema, A.S., van den Akker, T., Mfinanga, E.H., van Elteren, M. and van Roosmalen, J. (2012), "Barriers to conducting effective obstetric audit in Ifakara: a qualitative assessment in an under-resourced setting in Tanzania", Tropical Medicine \& International Health, Vol. 17 No. 5, pp. 652-7, doi: 10.1111/j.1365-3156.2012.02972.x.

Vink, N.M., De Jonge, H.C., Ter Haar, R., Chizimba, E.M. and Stekelenburg, J. (2013), "Maternal death reviews at a rural hospital in Malawi", International Journal of Gynecology \& Obstetrics, Vol. 120 No. 1, pp. 74-7.

Walton, M. (2004), "Creating a 'no blame' culture: have we got the balance right?”, Quality \& Safety in Health Care, Vol. 13 No. 3, pp. 163-4, doi: 10.1136/qshc.2004.010959.

WHO (2001), "WHO guidance for measuring maternal mortality from a census", available at: https://apps.who. int/iris/bitstream/handle/10665/87982/9789241506113eng.pdf;jsessionid=FF5ED2C93F58497C65C0 EEFA97AF497A?sequence $=($ accessed February 20, 2019).

WHO (2004), "Beyond the numbers: reviewing maternal deaths and complications to make pregnancy safer. Beyond the numbers: reviewing maternal deaths and complications to make pregnancy safer", available at: http://apps.who.int/iris/bitstream/handle/10665/42984/9241591838.pdf;jsessionid=f196cc8a63e380110 ee25c2dbdafe251? sequence=1 (accessed June 23, 2017).

WHO (2005), "The world health report 2005 - make every mother and child count", available at: www.who.int/ whr/2005/en/ (accessed September 20, 2018).

WHO (2006), "Making a difference in countries - strategic approach to improving maternal and newborn survival and health", available at: www.who.int/maternal_child_adolescent/documents/wa3102006ma/en/ (accessed September 20, 2018).

WHO (2010), "Integrating and strengthening maternal death surveillance and response in Malawi", available at: www.who.int/maternal_child_adolescent/epidemiology/maternal-death-surveillance/case-studies/ malawi/en/ (accessed March 20, 2018).

WHO (2011), Commission on Information and Accountability: Women's and Children's Health. Keeping Promises, Measuring Results, WHO, Geneva, available at: www.who.int/topics/millennium_development_ goals/accountability_commission/commission report_advance_copy.pdf (accessed June 20, 2018).

WHO (2013), "Maternal death surveillance and response: technical guidance information for action to prevent maternal death", available at: www.who.int/maternal_child_adolescent/documents/maternal_death_ surveillance/en/ (accessed June 20, 2018).

WHO (2016), "Standards for improving quality of maternal and newborn care in health facilities", available at: www.who.int/maternal_child_adolescent/documents/improving-maternal-newborn-care-quality/en/ (accessed March 20, 2018).

World Bank (2011), "Maternal death audit as a tool reducing maternal mortality", available at: http:// siteresources.worldbank.org/intprh/resources/376374-278599377733/maternaldeathauditmarch22011.pdf (accessed January 29, 2018). 


\section{Further reading}

Buchmann, E.J. (2014), "Towards greater effectiveness of perinatal death audit in low- and middle-income countries", BJOG: An International Journal of Obstetrics and Gynaecology, Vol. 121 No. S4, pp. 134-6, doi: 10.1111/1471-0528.12904.

Kenya Ministry of Health (2016), National Guidelines for Maternal and Perinatal Death Surveillance and Response, Ministry of Health-Kenya, Nairobi.

KMHPS (2009), Maternal Death Review Guidelines, Ministry of Health and Public Sanitation, Nairobi, available at: www.health.go.ke/wp-content/uploads/2016/04/kenya-hrh-strategy-2014-2018.pdf (accessed September 16, 2018).

Oestergaard, M.Z., Inoue, M., Yoshida, S., Mahanani, W.R., Gore, F.M., Cousens, S. et al. (2011), "Neonatal mortality levels for 193 countries in 2009 with trends since 1990: a systematic analysis of progress, projections, and priorities", PLOS Medicine, Vol. 8 No .8, p. e1001080, available at: https://doi.org/10.1371/ journal.pmed.1001080

UNICEF (2015), "Maternal mortality", available at: https://data.unicef.org/topic/maternal-health/maternalmortality/ (accessed January 1, 2018).

UNICEF (2018), "Levels and trends in child mortality", available at: https://data.unicef.org/wp-content/ uploads/2018/10/Child-Mortality-Report-2018.pdf (accessed August 13, 2018).

WHO (2018), "Maternal mortality", available at: www.who.int/news-room/fact-sheets/detail/maternalmortality (accessed August 20, 2018). 


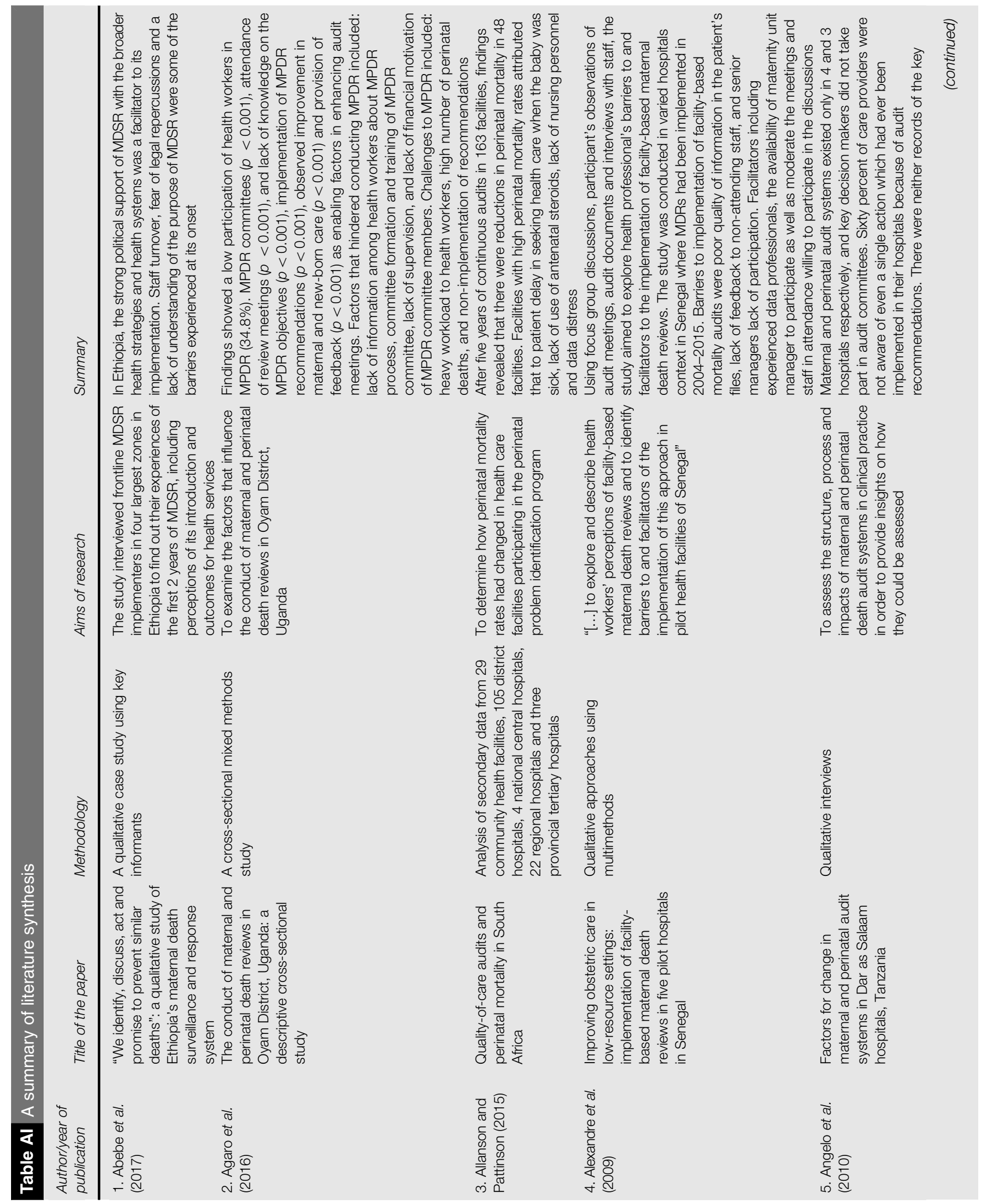




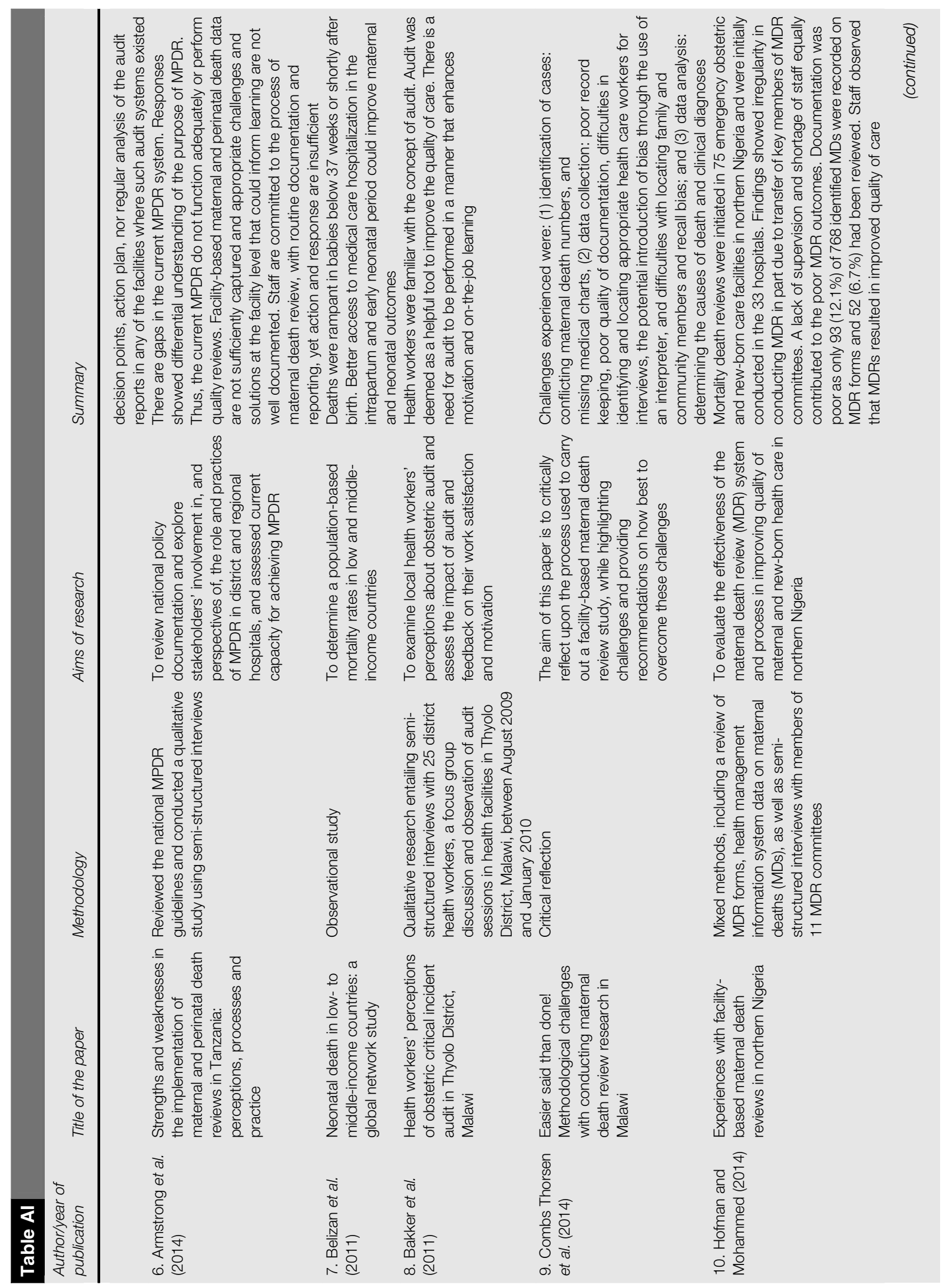




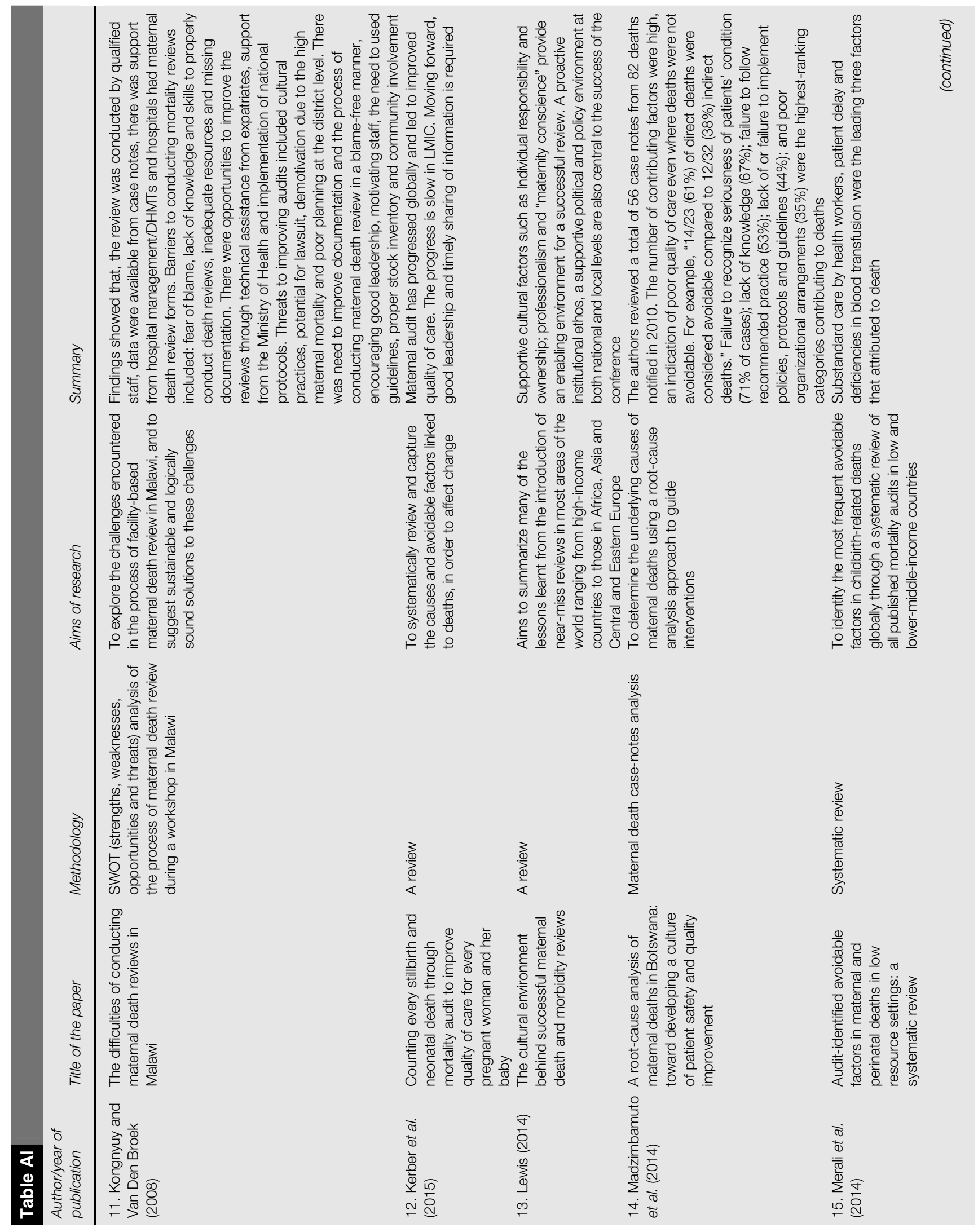




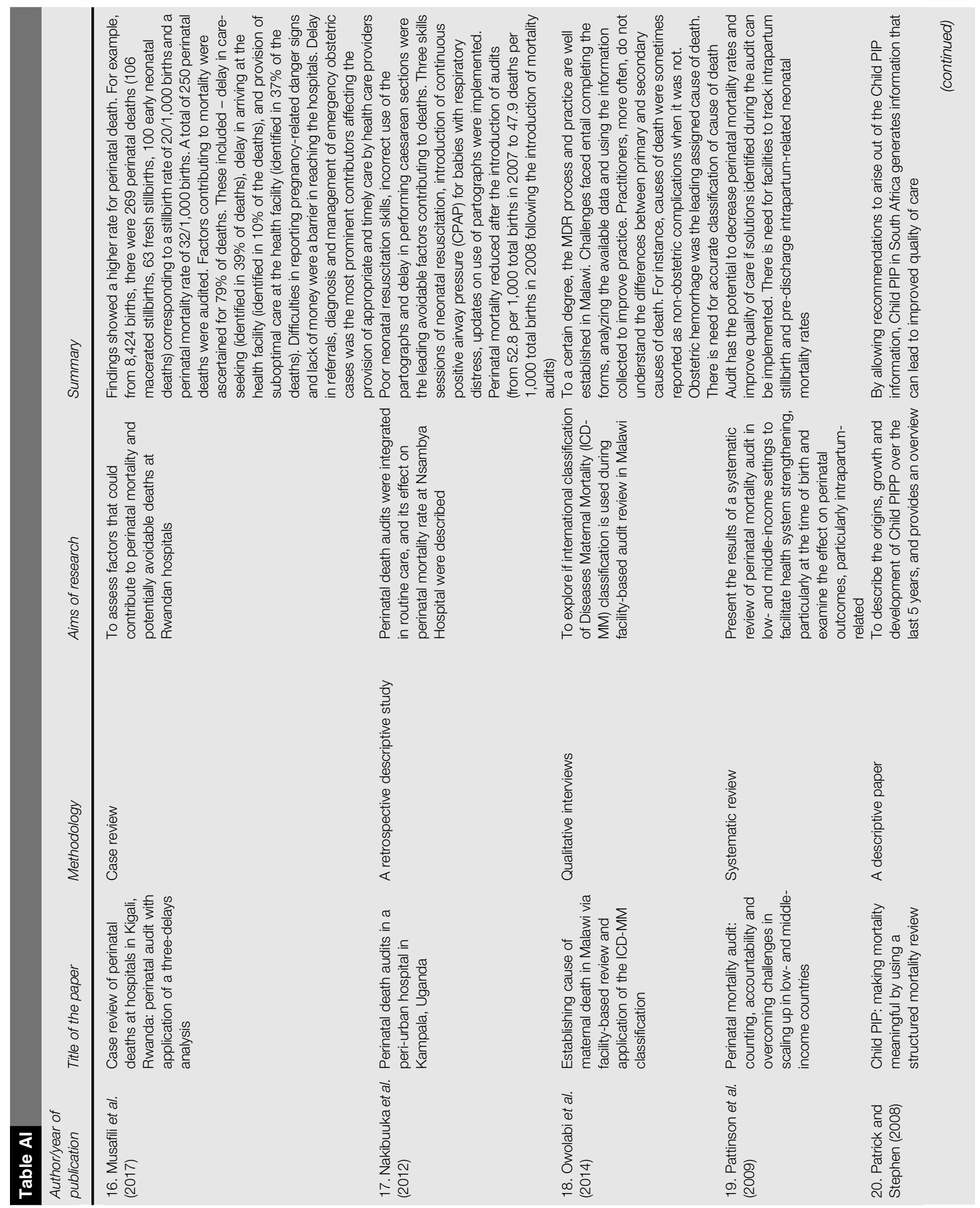




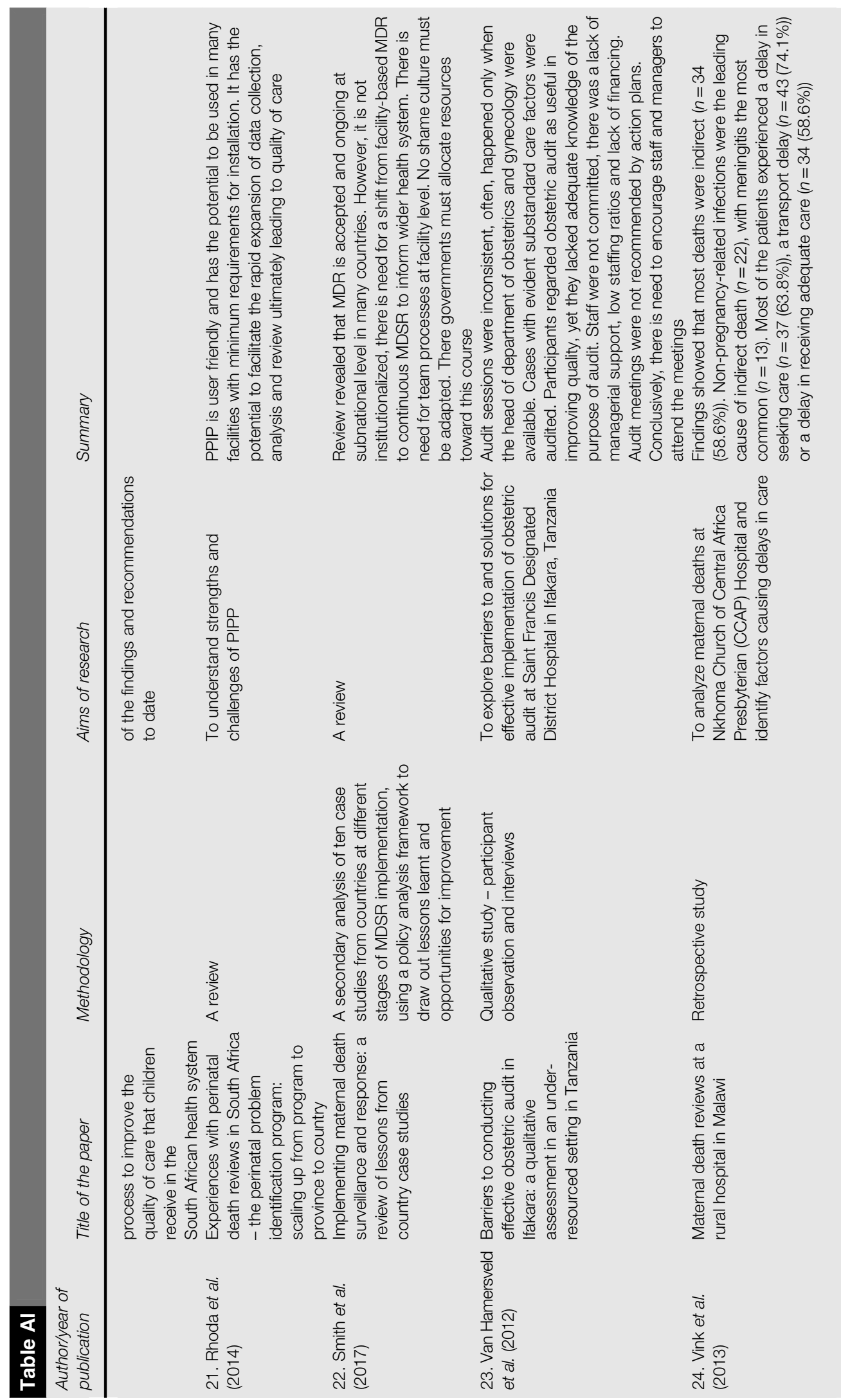




\section{Appendix 2}

Table All Non-peer-reviewed policy and government reports

Publishing

organization Summary

1. WHO (2016)

This was a Global survey of national MDSR systems conducted in 2015 by WHO and UNFPA to find out the global implementation of maternal death surveillance and response (MDSR). The findings revealed that although there was a widespread adoption of important elements of the MDSR system, many of the countries had not started using MDSR. Where national polices existed, they did not automatically guarantee the application of MDSR principles and processes at subnational level. Still, the findings showed that the existence of national and subnational maternal death review committees in some countries does not guarantee that these committees were functioning. Of concern, is the disparity between the percentage of countries with a national policy for notification of maternal deaths (86\%) and the application of the policy on the ground

2. World Bank (2011) This report discusses the importance of maternal death audits and the need of accurate systems of national MM rates, why MMA are important, approaches for reviewing maternal deaths and ill health as well as guidelines for establishing facility-based maternal audits

3. $\mathrm{KMOH}(2014 \mathrm{a}, \mathrm{b}) \quad$ This report details the first confidential inquiry into maternal deaths in Kenya to evaluate the circumstances surrounding mother's death. In total, 484 deaths occurring in the referral hospitals in Kenya were reviewed. Causes of death were accrued to deficiency in the care of mothers, blood loss, hypertensive disorders, pre-existing conditions such as HIV and anaemia. Following this report, a National Maternal and Perinatal Death Surveillance and Response (MPDSR) Committee and a National MPDSR secretariat were established

4. WHO (2013) This is a policy document that explains the critical concepts of Maternal Death Surveillance and Response (MDSR), and specific instructions for implementing each aspect of MDSR

\section{Author affiliations}

Adelaide Lusambili, Joyline Jepkosgei and Jacinta Nzinga are all based at Health Service Delivery Network, KEMRI-Wellcome Trust Research Program (KWTRP), Nairobi, Kenya.

Mike English is based at Kemri-Wellcome Trust Research Program (KWTRP), Nairobi, Kenya.

For instructions on how to order reprints of this article, please visit our website:

www.emeraldgrouppublishing.com/licensing/reprints.htm

Or contact us for further details: permissions@emeraldinsight.com 